\title{
RESEARCH
}

Open Access

\section{Spatiotemporal parameters and gait variability in people with psoriatic arthritis (PsA): a cross-sectional study}

\author{
Roua Walha ${ }^{1}$, Nathaly Gaudreault ${ }^{1}$, Pierre Dagenais ${ }^{1}$ and Patrick Boissy ${ }^{1,2^{*}}$ (D)
}

\begin{abstract}
Background: Foot involvement is a major manifestation of psoriatic arthritis (PsA) and can lead to severe levels of foot pain and disability and impaired functional mobility and quality of life. Gait spatiotemporal parameters (STPs) and gait variability, used as a clinical index of gait stability, have been associated with several adverse health outcomes, including risk of falling, functional decline, and mortality in a wide range of populations. Previous studies showed some alterations in STPs in people with PSA. However, gait variability and the relationships between STPs, gait variability and self-reported foot pain and disability have never been studied in these populations. Body-worn inertial measurement units (IMUs) are gaining interest in measuring gait parameters in clinical settings.
\end{abstract}

Objectives: To assess STPs and gait variability in people with PSA using IMUs, to explore their relationship with selfreported foot pain and function and to investigate the feasibility of using IMUs to discriminate patient groups based on gait speed-critical values.

Methods: Twenty-one participants with PsA (age: $53.9 \pm 8.9$ yrs.; median disease duration: 6 yrs) and 21 age- and sex-matched healthy participants (age $54.23 \pm 9.3 \mathrm{yrs}$ ) were recruited. All the participants performed three 10-m walk test trials at their comfortable speed. STPs and gait variability were recorded and calculated using six body-worn IMUs and Mobility Lab software (APDM ${ }^{\circledast}$ ). Foot pain and disability were assessed in participants with PsA using the foot function index (FFI).

Results: Cadence, gait speed, stride length, and swing phase were significantly lower, while double support was significantly higher, in the PSA group $(p<0.006)$. Strong correlations between STPs and the FFI total score were demonstrated $(|r|>0.57, p<0.006)$. Gait variability was significantly increased in the PsA group, but it was not correlated with foot pain or function $(p<0.006)$. Using the IMUs, three subgroups of participants with PsA with clinically meaningful differences in self-reported foot pain and disability were discriminated.

Conclusion: STPs were significantly altered in participants with PSA, which could be associated with self-reported foot pain and disability. Future studies are required to confirm the increased gait variability highlighted in this study and its potential underlying causes. Using IMUs has been useful to objectively assess foot function in people with PsA.

Trial registration: ClinicalTrials.gov, NCT05075343, Retrospectively registered on 29 September 2021.

Keywords: Psoriatic arthritis, Foot pain, Foot function, Spatiotemporal parameters, Gait variability, Gait analysis

\footnotetext{
*Correspondence: Patrick.Boissy@usherbrooke.ca

${ }^{1}$ Faculty of Medicine and Health Sciences, Université de Sherbrooke, Sherbrooke, QC, Canada

${ }^{2}$ Research Center on Aging, CIUSSS Estrie CHUS, Sherbrooke, QC, Canada
}

\section{$\triangle B M C$}

(c) The Author(s). 2022 Open Access This article is licensed under a Creative Commons Attribution 4.0 International License, which permits use, sharing, adaptation, distribution and reproduction in any medium or format, as long as you give appropriate credit to the original author(s) and the source, provide a link to the Creative Commons licence, and indicate if changes were made. The images or other third party material in this article are included in the article's Creative Commons licence, unless indicated otherwise in a credit line to the material. If material is not included in the article's Creative Commons licence and your intended use is not permitted by statutory regulation or exceeds the permitted use, you will need to obtain permission directly from the copyright holder. To view a copy of this licence, visit http://creativecommons.org/licenses/by/4.0/ The Creative Commons Public Domain Dedication waiver (http://creativecommons.org/publicdomain/zero/1.0/) applies to the data made available in this article, unless otherwise stated in a credit line to the data. 


\section{Background}

Psoriatic arthritis (PsA) is a chronic inflammatory arthropathy associated with skin psoriasis and belongs to the spondyloarthropathy family. Several musculoskeletal manifestations can occur during the disease course, and both axial and peripheral joints can be affected. The foot and the ankle are common targets of inflammation and their involvement could be a major manifestation of the disease in terms of frequency and severity [1-3]. Foot and ankle problems include dactylitis, enthesitis, synovitis, and tenosynovitis and can lead to foot and/or ankle pain, stiffness, swelling, and deformity [4-8]. Consequently, a high proportion of patients could experience moderate to high levels of foot impairment and difficulties with activities of daily living that require good foot function, such as walking $[3,4,9]$.

Pain and physical function are identified among the most important clinical domains to be measured in PsA clinical studies by the Group for Research and Assessment of Psoriasis and Psoriatic arthritis (GRAPPA) [10]. While patient-reported outcomes are commonly used to assess pain and perceived function, gait analysis could be used to obtain objective measures of physical function [11] In people with inflammatory joint disease, including rheumatoid arthritis (RA) and PsA, different gait parameters of varying complexity, such as joint kinetics and kinematics, plantar pressure, and spatiotemporal parameters (STPs), have been employed to assess either global function or localized foot function [12-14]. Among these parameters, STPs, which typically encompass gait speed, stride length, cadence, double support, and swing time present certain ease of interpretability by both clinicians and patients and have great utility in predicting health outcomes. For example, a reduced gait speed was associated with an increased risk of falling [15], functional decline [16] and mortality in older adults [17]. Gait speed was also designated the 6th vital sign, and precise cut-off values have been used to predict specific outcomes in older adults $[18,19]$. Both the STP mean values and the variation around them, referred to as gait variability, are key metrics in gait evaluation [20]. Gait variability is used as a clinical index for gait stability [21] and is associated with an increased risk of falling in older adults [22].

Importantly, STPs and gait variability can now easily be measured with emerging lightweight, low-cost, and easy-to-use wearable inertial measurement units (IMUs). These latter have shown acceptable accuracy and precision in measuring STPs in people with PsA and axial spondyloarthritis [23, 24].

Many studies investigated gait STPs in people with RA with foot involvement and showed significant alterations in gait STP which included reduced gait speed, stride length and cadence, and increased double support [14].
However, there are scarce data on gait STPs in people with spondyloarthritis, including PsA [14, 25]. For instance, a recent study demonstrated changes in gait STPs including reduced gait speed, stride length, and swing time, and increased double support time, which were associated with self-reported pain in people with axial spondyloarthritis [26]. Similar changes were reported in a few studies in people with PsA [5, 27, 28]. For example, Hyslop et al. assessed cadence, gait speed, stride length, and double support time in people with PsA with and without enthesitis and showed that stride length was significantly lower in the PsA group with enthesitis [27]. A study by Woodburn et al., which was based on the same cohort as Hyslop et al., showed a significant decrease in gait speed in a PsA group with enthesitis compared to healthy controls [28]. On the other hand, Wilkins et al. investigated cadence, gait speed, and double support time in people with PsA with and without active dactylitis. Their findings showed a decreased gait speed and increased double support in both PsA groups. However, no significant differences were demonstrated compared to the control group. This could be explained by the small sample size, the relatively young mean age of the study participants $(36.7 \pm$ 21.5 years) and the short disease duration (4.6 \pm 6.7 years), which were previously shown to be correlated with gait parameters in people with RA [5, 29].

Overall, the above studies demonstrate alterations in gait STPs. However, despite including participants with confirmed foot involvement, it is not clear whether altered gait STPs are associated with self-reported foot pain and disability. On another note, the reported alterations could be indicative of increased gait instability since such changes are characteristics of cautious gait patterns that are typically undertaken by older adults to increase stability [30]. In fact, a few recent studies demonstrated altered static and dynamic balance [31, 32] and increased risk of falling in people with PsA [33]. Fall-related risk factors have not been studied in people with PsA. Nevertheless, research in RA showed that swollen and tender lower extremity joints were among the most significant fall-related risk factors [34]. Taking all this into account, despite being a relevant and easyto-measure gait parameter, no previous research has investigated gait variability and its relationship with selfreported foot pain and function in people with PsA.

Thus, given the limited evidence regarding STPs, gait variability, and their relationship with foot pain and disability in people with PsA, this study aimed 1) to investigate STPs and gait variability in participants with PsA with foot pain and compare them to age- and sexmatched healthy participants using body-worn IMUs, 2) to explore the relationship between STPs, gait variability, and self-reported foot pain and disability, and 3) to 
investigate the feasibility of using body-worn IMUs to discriminate patient groups based on gait speed-critical values.

\section{Methods}

\section{Study design}

A portion of the data presented in this descriptive crosssectional study pertains to an ongoing pre-experimental trial exploring the effects of custom-made foot orthoses on foot pain and function and gait STPs in people with PsA. Baseline gait STP measures in participants with PsA captured during a standardized $10-\mathrm{m}$ walk within this pre-experimental study were compared to age- and sex-matched controls undergoing the same clinical gait evaluation protocol.

\section{Participants}

Twenty-one participants with PsA were consecutively recruited from the rheumatology outpatient clinics at the Hotel Dieu University Hospital CHU of Sherbrooke (CHUS). Inclusion criteria were the following: being between 20 and 70 years of age, having a rheumatologistconfirmed PsA diagnosis, having recurrent and moderate ( $>3$ points) to severe ( $>6$ points) foot pain as reported on a 0 to 10 numerical rating scale [35], and receiving stable medication for at least the three months preceding recruitment. Exclusion criteria applied to patients with diabetes, neurological disease, or any musculoskeletal disease that could impact normal gait patterns. Patients who received intra-articular corticosteroid injections or any conservative foot treatment, such as foot orthoses, within the past three months were excluded because they may influence their gait. Twentyone control participants matched for age and sex with no self-reported foot/ankle problems were also recruited using flyers posted in the research center and the wordof-mouth strategy. They had to be devoid of a current or recent history of foot/ankle pain and self-reported gait deficits. The study was approved by the CIUSSS de l'Estrie-CHUS Institutional Review Board and all the participants provided written informed consent.

\section{Data collection procedure}

Upon their arrival at the Université de Sherbrooke Research Center on Aging, demographic data, including sex, age, body mass index (BMI), and foot and lower limb pain, were obtained for all participants (PsA and controls). Perceived foot function was additionally assessed in PsA participants. Afterward, an instrumented gait analysis was performed for each participant (PsA and controls). Disease-related information was obtained for participants with PsA from their medical records.

\section{Outcomes and measurement tools Clinical parameters}

Disease characteristics Disease duration, current medication, and C-reactive protein (CRP) levels, as a marker of systemic inflammation, were obtained from the patient's medical record.

Foot and lower limb pain Given that lower limb and lower back pain are not uncommon in people with PsA and that they could affect gait patterns [26, 36-39], knee, hip, and lower back pain were assessed in addition to foot pain using the numerical rating scale (NRS) in participants with PsA and healthy controls. Participants were asked to circle a number between 0 and 10 that best fits their average pain intensity experienced in the foot, knee, hip, and lower back over the seven days preceding the data collection. Moreover, all the participants in the PsA group were examined by a trained podiatrist with eight years of professional clinical experience, in an independent podiatry clinic. Pain sites and deformities at the feet were documented from the podiatrist's clinical examination record.

Foot function Foot function was measured in the PsA group with the Foot Function Index (FFI), a reliable and valid questionnaire that has been proven suitable for use in people with foot disorders and a low functioning status $[40,41]$. The FFI was chosen to be used in this study because it has a validated version in French [42]. The FFI comprises 23 items divided into three sub-scales measuring foot pain (FFI-Pain), foot disability (FFI-Disability), and foot-related activity limitation (FFI-Activity Limitation). Each FFI item is recorded on an NRS (0 to 10). A total score and three sub-scale scores were calculated. For an easier interpretation, the scores are presented as percentages, where a higher percentage indicates higher levels of foot pain and related disability.

\section{Gait analysis}

Gait STPs presented and defined in Table 1 and Fig. 1A [44] were measured in participants with PsA and healthy controls using Opal IMUs and Mobility Lab software (APDM Wearable Technologies, Portland, OR, USA). The Mobility Lab has been validated in healthy and pathological populations such as Parkinson's disease [45-47]. The accuracy of this system was also assessed in people with PsA in a previous work that showed acceptable errors in measuring gait STPs recorded over a treadmill at a normal walking speed [23]. The mobility lab includes a set of six IMUs each with a triad of sensors (a 3-axis accelerometer, a 3-axis gyroscope, and a 3axis magnetometer) (Fig. 1. C), an access point for wireless data transmission and synchronization and software 
Table 1 Gait Spatiotemporal Parameters (SPTs), measurement units, and definitions

\begin{tabular}{|c|c|c|}
\hline Variables & Units & Definitions \\
\hline Cadence & $\begin{array}{l}\text { Step/minute } \\
\text { (step/min) }\end{array}$ & Number of steps per minute \\
\hline Gait speed & $\begin{array}{l}\text { Meter/second } \\
(\mathrm{m} / \mathrm{s})\end{array}$ & $\begin{array}{l}\text { The forward speed of the subject, measured as the forward distance traveled during the gait cycle divided by } \\
\text { the gait cycle duration. }\end{array}$ \\
\hline Stride length & Meters (m) & The forward distance traveled by a foot during a gait cycle. \\
\hline $\begin{array}{l}\text { Double support } \\
\text { time }\end{array}$ & $\%$ GCT & The percentage of the gait cycle in which both feet are on the ground. \\
\hline Swing time & $\% \mathrm{GCT}$ & The percentage of the gait cycle in which the foot is not on the ground. \\
\hline $\begin{array}{l}\text { Foot strike } \\
\text { angle }\end{array}$ & degrees & $\begin{array}{l}\text { The angle of the foot dorsiflexion at the point of initial contact. The pitch of the foot when flat is zero and } \\
\text { positive when the heel contacts first. }\end{array}$ \\
\hline $\begin{array}{l}\text { Stride time } \\
\text { variability }\end{array}$ & $\%$ & $\begin{array}{l}\text { The percentage of each participant's standard deviation of stride time is divided by the same parameter mean } \\
\text { value. }\end{array}$ \\
\hline
\end{tabular}

(Mobility Lab) that provides an automated estimation of several STPs (Table 1). Details on the algorithm allowing for STP calculation with the Mobility Lab system have been previously described [48].

All the participants performed three trials of the 10-m walk test (10MWT) (Fig. 1. B), which consists of walking over a 14-m straight walkway at a comfortable speed. Two extra meters at the beginning and the end of the trials were added to account for the acceleration and deceleration, and only the central $10 \mathrm{~m}$ were considered for the analysis (Fig. 1. B). The participants were asked to walk at their usual preferred self-selected speed wearing comfortable walking shoes, and none of the participants used foot orthoses or modified footwear. The Mobility Lab IMUs were fixed with elastics straps on the chest, the lower back, and both wrists and feet as recommended by the manufacturer's instructions (Fig. 1. C).

Stride time variability was chosen as a measure of gait variability, as it is the most commonly reported parameter in clinical studies [49]. This metric was calculated

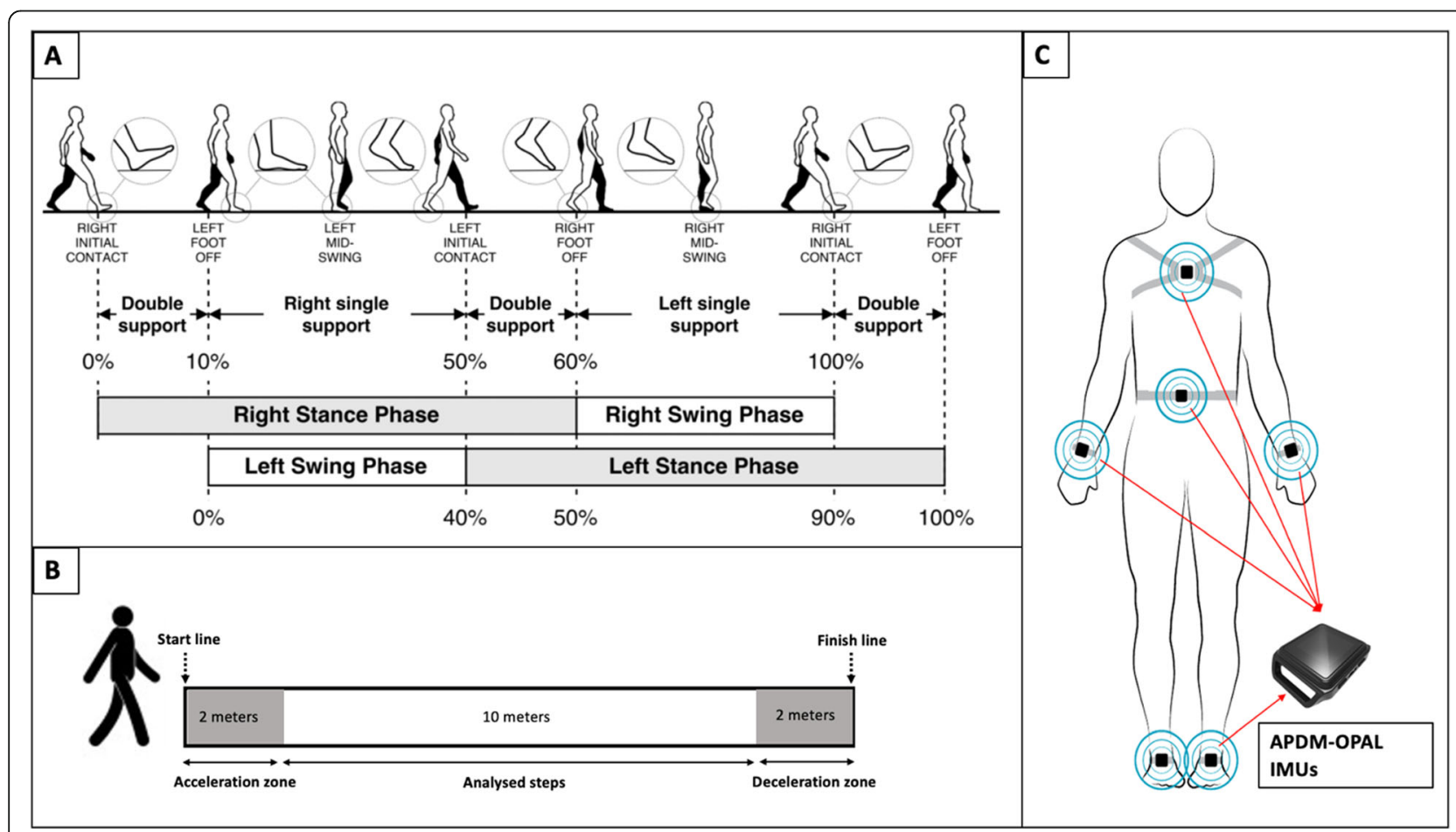

Fig. 1 A The gait cycle phases taken from an open access article [40]; B $10 \mathrm{~m}$ walk test (10MWT); C The Mobility Lab sensors placement 
as the coefficient of variation $(\mathrm{CV})$, defined as the percentage of each participant's standard deviation of stride time divided by its mean value:

$$
\mathrm{CV}=\frac{\mathrm{SD}}{\text { Mean }} \times 100 \%
$$

\section{Statistical analysis}

Based on data from a previous study comparing gait parameters between people with PsA diagnosed with rearfoot enthesitis and healthy controls [27], an average effect size was calculated from the means and standard deviations reported for cadence, gait speed, stride length, and double support time. Given the calculated effect size $(\mathrm{d}=$ 0.8 ), a total sample size of 32 participants (16 per group) was required to detect significant differences in gait STPs with a paired t-test at an $\alpha$ of 0.01 and a power of 0.95 .

The Shapiro-Wilk test was used to examine data distribution. Paired t-tests and the Wilcoxon signed-rank test were used to assess the differences in gait STPs and stride time variability between participants with PsA and matched healthy controls, and Cohen's effect size was calculated to quantify the magnitude of these differences. ANCOVA was used to adjust the differences in STPs between PsA and healthy participants for the effect of BMI. Pearson's and Spearman's correlation coefficients were calculated to assess the relationships between STPs, gait variability, and self-reported foot pain and function in participants with PsA. Correlation coefficients were considered weak, moderate and strong for values between 0.1 and $0.3,0.3$ and 0.5 , and $>0.5$, respectively [50]. Given the clinical relevance of gait speed and the availability of reference values for this metric, subgroups of participants with PsA were differentiated based on critical values of gait speed $(1.0 \mathrm{~m} / \mathrm{s}$ : the limit below which gait speed values are associated with higher mortality and $1.2 \mathrm{~m} / \mathrm{s}$ : the lower limit of the confidence interval for normative gait speed $[17,51])$. The relationships between gait speed, FFI total score and FFI subcategory scores for these three subgroups were visualized in scatter plots.

As multiple variables that may be highly correlated were tested, the Bonferroni correction method was used to reduce type I error resulting from multiple testing. Therefore, $P$ values $<0.006$ were considered statistically significant. Analyses were performed using SPSS version 26.0 (IBM SPSS, Armonk, NY).

\section{Results}

\section{Demographics and clinical characteristics}

Twenty-one participants with PsA (5 males, 16 females) with a mean age of $53.9 \pm 8.9$ years and a mean disease duration of $11.5 \pm 10.2$ years and 21 healthy controls ( 5 males, 16 females) with a mean age of $54.2 \pm 9.3$ years were included (Table 1). BMI was significantly higher in participants with PsA than in healthy controls $(29.3 \pm 4.5$ vs $24.4 \pm 3.4), p<0.001)$. Because of the different thresholds used by the laboratories, CRP levels are reported as normal or high. CRP levels were missing, high and normal for 4, 1 and 16 participants, respectively. Ninety percent of the patients were treated with disease-modifying anti-rheumatic drugs (DMARDs) and/or biological therapy.

The NRS scores showed moderate to severe levels of lower limb pain in the PsA group. 52.4 and $38.1 \%$ of the participants with PsA reported moderate and severe foot pain, respectively, while foot and lower limb pain levels were close to zero in healthy participants (Table 2). The FFI sub-scores also showed moderate to severe levels of self-reported foot pain $(55.7 \pm 18.3)$ and disability $(44.6 \pm 22.7)$ in participants with PsA. The most frequently reported pain sites at the feet were the ankles, followed by the metatarsals, toes, and heels (plantar and/ or posterior heel), and 18 (85\%) participants had simultaneous forefoot and rearfoot pain. Sixty-two percent of the participants in the PsA group had heel valgus, $67 \%$ had hammer/claw toes and 24 and 19\% had hallux valgus and hallux rigidus, respectively.

\section{Spatiotemporal parameters and gait variability in PsA and healthy participants}

Gait STPs for left and right foot in PsA and healthy participants are presented in Table 3 . There were significant differences between the two groups in all the measured STPs except for the foot strike angle of the right foot. STPs averaged for left and right foot and stride time variability adjusted for BMI in PsA and healthy participants are summarized in Table 4. Before adjusting the data for BMI, all STPs except for foot strike angle were significantly different between groups. Cadence, gait speed and stride length and swing time were significantly lower in participants with PsA, and large effect sizes were reported $(p<0.006 ; 1.08<\mathrm{d}<1.3)$ (Table 4$)$. Gait cycle duration and double support time were significantly higher in the PsA group, and large effect sizes were also reported $(p<0.006 ; \mathrm{d}=1.2$ and $\mathrm{d}=1.26)$ (Table 4). After adjusting the differences for BMI, only cadence, gait cycle duration, and gait speed remained significantly different between groups, while the differences in stride length $(p=0.026)$, double support $(p=$ $0.022)$, and swing time $(p=0.023)$ were no longer significant. Stride time variability was significantly higher in the PsA group before and after adjusting for BMI ( $p=$ 0.001 and $p=0.005)$, and a moderate effect size was reported $(\mathrm{d}=0.68)$ (Table 4$)$.

Three subgroups of participants with PsA (PsA1, PsA2, and PsA3) were differentiated based on gait 
Table 2 Demographics and clinical characteristics of participants with PsA and healthy participants

\begin{tabular}{|c|c|c|}
\hline \multirow[t]{2}{*}{ Variables } & PsA & CONTROLS \\
\hline & Mean \pm SD & Mean \pm SD \\
\hline AGE (years) & $53.9 \pm 8.9$ & $54.23 \pm 9.3$ \\
\hline BMI $\left(\mathrm{kg} / \mathrm{m}^{2}\right)$ & $29.3 \pm 4.5)$ & $24.4 \pm 3.4^{*}$ \\
\hline SEX (M: F) & 5: 16 & 5: 16 \\
\hline DISEASE DURATION (years) & $11.5 \pm 10.2$ (Median=6, IQR: 12) & - \\
\hline \multicolumn{3}{|l|}{ CRP (mg/l) } \\
\hline Normal & $16(94 \%)$ & \\
\hline High & $1(6 \%)$ & \\
\hline \multicolumn{3}{|l|}{ Pharmacological therapy } \\
\hline DMARDs & $6(30 \%)$ & \\
\hline Biological therapy & $5(25 \%)$ & \\
\hline DMARDs and Biological therapy & 7 (35\%) & \\
\hline Foot pain ( 0 to 10 points) & $5.6 \pm 1.9$ & $0.2 \pm 0.6^{*}$ \\
\hline Knee pain ( 0 to 10 points) & $4.7 \pm 2.6$ & $0.5 \pm 1.2^{*}$ \\
\hline Hip pain (0 to 10 points) & $4.8 \pm 2.9$ & $0.1 \pm 0.3^{*}$ \\
\hline Lower back pain ( 0 to 10 points) & $5.4 \pm 2.7$ & $1.6 \pm 2.5^{*}$ \\
\hline \multicolumn{3}{|l|}{ Foot function Index } \\
\hline FFI-Pain (\%) & $55.7 \pm 18.3$ & - \\
\hline FFI-Disability (\%) & $44.6 \pm 22.7$ & \\
\hline FFI-Activity limitation (\%) & $34.3 \pm 24.4$ & \\
\hline FFI-Total (\%) & $47.02 \pm 18.3$ & \\
\hline Pain sites & & - \\
\hline Toes & 15 (71\%) & \\
\hline Metatarsals & $16(76 \%)$ & \\
\hline Heels & $11(52 \%)$ & \\
\hline Ankles & 17 (81\%) & \\
\hline Deformities & & - \\
\hline Rearfoot valgus & $13(62 \%)$ & \\
\hline Hallux valgus & $5(24 \%)$ & \\
\hline Hallux rigidus & $4(19 \%)$ & \\
\hline Hammer/claw toes & $14(67 \%)$ & \\
\hline
\end{tabular}

Values are mean \pm standard deviation and percentages for categorial variables, $p$ values $<0.006$ are considered significant, ${ }^{*}: p<0.006$. $B M I$ body mass Index, $M$ males, $F$ females, FFI foot function index

Table 3 Spatiotemporal parameters (STPs) for left and right foot in participants with PSA and healthy matched controls

\begin{tabular}{|c|c|c|c|c|c|c|}
\hline \multirow[t]{2}{*}{ Variable } & \multicolumn{2}{|c|}{ PsA participants } & \multicolumn{2}{|c|}{ Control participants } & \multicolumn{2}{|c|}{$p$-value } \\
\hline & Left & Right & $\overline{\text { Left }}$ & Right & Left & Right \\
\hline Cadence (step/min) & $108.1 \pm 10.8$ & $107.7 \pm 10.8$ & $120 \pm 6.8$ & $119.9 \pm 6.9$ & 0.000 & 0.000 \\
\hline Gait cycle duration (s) & $1.1 \pm 0.1$ & $1.1 \pm 0.1$ & $1 \pm 0.1$ & $1 \pm 0.1$ & 0.000 & 0.000 \\
\hline Gait speed $(\mathrm{m} / \mathrm{s})$ & $1.1 \pm 0.2$ & $1.1 \pm 0.2$ & $1.4 \pm 0.2$ & $1.3 \pm 0.2$ & 0.000 & 0.000 \\
\hline Stride length (m) & $1.2 \pm 0.2$ & $1.2 \pm 0.2$ & $1.4 \pm 0.2$ & $1.3 \pm 0.1$ & 0.001 & 0.001 \\
\hline Double support time (\% GCT) & $21.9 \pm 4.1$ & $22.1 \pm 4.1$ & $17.8 \pm 2.7$ & $18 \pm 2.7$ & 0.000 & 0.000 \\
\hline Swing time (\% GCT) & $39.4 \pm 1.9$ & $38.6 \pm 2.4$ & $41.3 \pm 1.4$ & $40.8 \pm 1.4$ & 0.001 & 0.000 \\
\hline Foot strike angle (degrees) & $25.3 \pm 4.1$ & $24.7 \pm 3.9$ & $28.6 \pm 2.7$ & $27.7 \pm 3.7$ & 0.008 & 0.015 \\
\hline
\end{tabular}

Values are Mean \pm standard deviation, $p$ values $<0.006$ are considered significant PSA Psoriatic arthritis, GCT gait cycle time 
Table 4 Spatiotemporal parameters (STPS) averaged for left and right foot and stride time variability in participants with PsA and healthy matched controls before and after adjustment for BMI

\begin{tabular}{|c|c|c|c|c|c|}
\hline \multirow[t]{2}{*}{ Variables } & \multicolumn{2}{|c|}{ PsA participants } & \multicolumn{2}{|c|}{ Control participants } & \multirow{2}{*}{$\begin{array}{l}\text { Cohen's } \\
\text { d }\end{array}$} \\
\hline & Mean \pm SD & Adj Mean (SE) & Mean \pm SD & Adj Mean (SE) & \\
\hline Cadence (step/min) & $107.91 \pm 10.78$ & $107.47(2.12)$ & $120.08 \pm 6.8^{\mathrm{a}}$ & $120.55(2.17)^{b}$ & 1.3 \\
\hline Gait cycle duration (s) & $1.13 \pm 0.14$ & $1.13(0.03)$ & $1.00 \pm 0.06^{\mathrm{a}}$ & $1.00(0.03)^{b}$ & 1.2 \\
\hline Gait speed $(\mathrm{m} / \mathrm{s})$ & $1.07 \pm 0.23$ & $1.10(0.05)$ & $1.35 \pm 0.2^{\mathrm{a}}$ & $1.38(0.06)^{b}$ & 1.3 \\
\hline Stride length (m) & $1.17 \pm 0.18$ & $1.19(0.04)$ & $1.34 \pm 0.13^{\mathrm{a}}$ & $1.32(0.04)$ & 1.08 \\
\hline Double support (\% GCT) & $22.00 \pm 4.13$ & $21.43(0.79)$ & $17.95 \pm 2.7^{\mathrm{a}}$ & $18.55(0.81)$ & 1.16 \\
\hline Swing time (\% GCT) & $39.0 \pm 2.08$ & $39.28(0.40)$ & $41.03 \pm 1.36^{\mathrm{a}}$ & $40.73(0.41)$ & 1.15 \\
\hline Foot strike angle (degrees) & $24.99 \pm 3.79$ & $25.16(0.80)$ & $28.15 \pm 2.97^{\mathrm{a}}$ & $27.97(0.82)$ & 0.92 \\
\hline Stride time variability (\%) & $4.03 \pm 3.56$ & $4.49(0.58)$ & $2.32 \pm 0.72^{\mathrm{a}}$ & $1.84(0.60)^{b}$ & 0.68 \\
\hline
\end{tabular}

Values are mean \pm standard deviation and adjusted mean (Standard error)

PsA Psoriatic arthritis, Adj adjusted mean, SE Standard error, $d$ Cohen's effect size, GCT gait cycle time

${ }^{a}$ Significant differences in mean values between PsA and healthy participants

${ }^{\mathrm{b}}$ Significant differences in adjusted mean values between PsA and healthy participants

speed-critical values. Patients in PsA1 had gait speed values below $1.0 \mathrm{~m} / \mathrm{s}$ with a mean gait speed of $0.81 \pm$ $0.16 \mathrm{~m} / \mathrm{s}$; PsA2 included patients with gait speed values between $1.0 \mathrm{~m} / \mathrm{s}$ and $1.2 \mathrm{~m} / \mathrm{s}$, and the mean gait speed for this subgroup was $1.08 \pm 0.05 \mathrm{~m} / \mathrm{s}$; and PsA3 was composed of patients with gait speed values greater than $1.2 \mathrm{~m} / \mathrm{s}$ with a mean gait speed of $1.34 \pm 0.1 \mathrm{~m} / \mathrm{s}$. PsA1,
PsA2 and PsA3 represented 32, 41 and 27\% of the total sample, respectively.

Relationship between STP, gait variability, and clinical parameters

Correlation coefficients between STPs, stride time variability and clinical parameters in participants with PsA

\begin{tabular}{|c|c|c|c|c|c|c|c|c|c|c|c|c|}
\hline & 1 & 2 & 3 & 4 & 5 & 6 & 7 & 8 & 9 & 10 & 11 & 12 \\
\hline 1. FFI-Pain & 1.00 & 0.48 & 0.74 & 0.77 & -0.42 & 0.40 & $-0.65 \mid$ & -0.67 & 0.63 & $-0.64 \mid$ & -0.71 & 0.10 \\
\hline 2. FFI-Disability & 0.48 & 1.00 & 0.63 & 0.88 & -0.62 & 0.61 & $-0.78 \mid$ & -0.71 & 0.61 & $-0.62 \mid$ & -0.63 & 0.26 \\
\hline 3. FFI-Activity Limitation & 0.74 & 0.63 & 1.00 & 0.86 & -0.42 & 0.40 & $-0.68 \mid$ & -0.64 & 0.77 & $-0.80 \mid$ & -0.54 & 0.02 \\
\hline 4. FFI-Total & 0.77 & 0.88 & 0.86 & 1.00 & -0.59 & 0.57 & $-0.87 \mid$ & -0.83 & 0.79 & $-0.80 \mid$ & -0.75 & 0.16 \\
\hline 5. Cadence & -0.42 & -0.62 & -0.42 & -0.59 & 1.00 & $\mid-1.00$ & 0.78 & 0.56 & -0.51 & 0.52 & 0.58 & -0.34 \\
\hline 6. Gait cycle duration & 0.40 & 0.61 & 0.40 & 0.57 & -1.00 & 1.00 & -0.77 & -0.56 & 0.49 & -0.51 & -0.58 & 0.34 \\
\hline 7. Gait speed & $-0.65 \mid$ & -0.78 & -0.68 & -0.87 & 0.78 & $|-0.77|$ & 1.00 & 0.94 & -0.76 & 0.77 & 0.75 & -0.23 \\
\hline 8. stride length & -0.67 & -0.71 & -0.64 & -0.83 & 0.56 & -0.56 & 0.94 & 1.00 & -0.76 & 0.77 & 0.72 & -0.15 \\
\hline 9. Double support & 0.63 & 0.61 & 0.77 & 0.79 & -0.51 & 0.49 & -0.76 & -0.76 & 1.00 & -1.00 & -0.59 & 0.15 \\
\hline 10. Swing time & -0.64 & -0.62 & -0.80 & -0.80 & 0.52 & -0.51 & 0.77 & 0.77 & -1.00 & 1.00 & 0.59 & -0.15 \\
\hline 11. Foot strike angle & -0.71 & -0.63 & -0.54 & -0.75 & 0.58 & -0.58 & 0.75 & 0.72 & -0.59 & 0.59 & 1.00 & \\
\hline 12. Stride time CV & 0.10 & 0.26 & 0.02 & 0.16 & -0.34 & 0.34 & -0.23 & -0.15 & 0.15 & -0.15 & & 1.00 \\
\hline
\end{tabular}

Fig. 2 Correlation matrix of the relationships between spatiotemporal parameters, stride time variability and the foot function index 
are presented in Fig. 2. All the STPs were strongly and significantly correlated with the FFI total score and the disability sub-score $(0.57<|\mathrm{r}|<0.87, p<0.006)$. All the STPs except for cadence and gait cycle duration were correlated with the pain and activity limitation subscores $(0.63<|\mathrm{r}|<0.8, p<0.006)$ (Fig. 2). Gait speed had the highest correlation coefficients with the FFI total score $(\mathrm{r}=-0.87)$ and the disability sub-score $(\mathrm{r}=-0.78)$, while foot strike angle had the highest correlations with the pain sub-score (FFI-Pain) $(\mathrm{r}=-0.71)$. Swing time $(r=-0.80)$ had the highest correlations with the activity limitation sub-score (FFI-Activity limitation). Regarding gait variability, there was no significant correlation between stride time $\mathrm{CV}$ and clinical parameters of foot pain and disability.

The relations between gait speed and the total FFI score and sub-scores for PsA subgroups (PsA1, PsA2, and PsA3) are presented in Fig. 3. Participants in PsA1 had the highest scores on all the sub-scales and the total FFI compared to PsA2 and PsA3 (FFI-Total: 62.21 \pm $11.36 \%$ for PsA1, vs $48.68 \pm 12.36 \%$ and $26.83 \pm 11.14 \%$ for PsA2 and PsA3, respectively). Knowing that the minimal clinically important difference (MCID) for the FFI total score is equal to 7\%, the differences in the FFI total scores found between these subgroups were clinically meaningful.

It was theorized that CRP levels, disease duration, knee pain, hip pain, and lower back pain would affect STPs and interfere with their relationship with the FFI. However, none of these potential confounders was correlated with STPs except for knee pain, which was moderate with foot strike angle $(\mathrm{r}=-0.48, p=0.028)$, but the strength of the relationship did not reach the significance level.
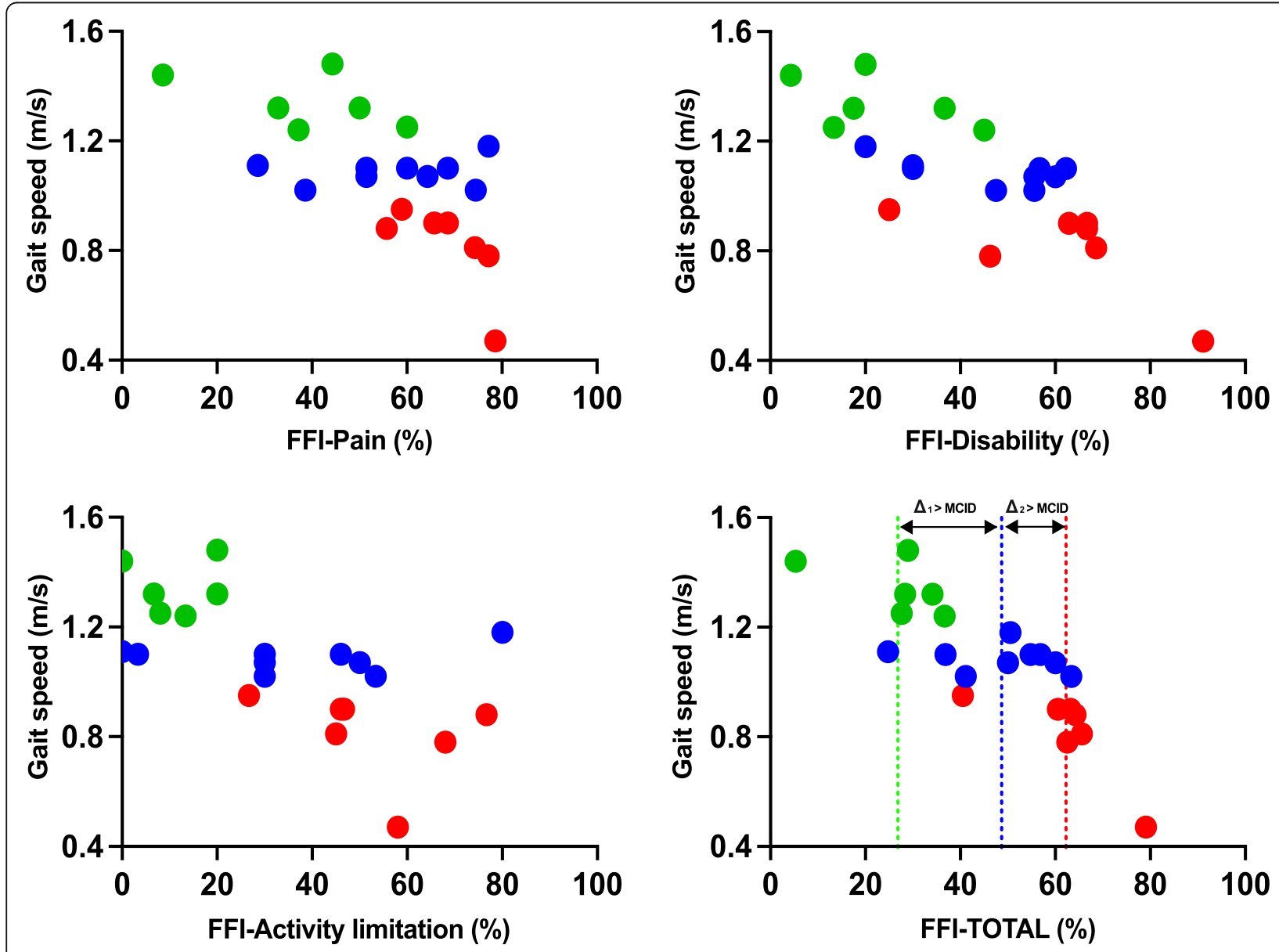

PsA1: Gait speed $<1.0 \mathrm{~m} / \mathrm{s}$ PsA2: $1.0 \mathrm{~m} / \mathrm{s}<$ Gait speed $<1.2 \mathrm{~m} / \mathrm{s}$

PsA3: Gait speed $>1.2 \mathrm{~m} / \mathrm{s}$

\section{- - - Mean FFI total score for PsA1 - - Mean FFI total score for PsA2 = - Mean FFI total score for PsA3}

Fig. 3 Scatter plots of the relationships between gait speed and the foot function index for PsA subgroups. PsA1 Participants with gait speed below $1.0 \mathrm{~m} / \mathrm{s}$, PSA2 participants with gait speed comprised between 1.0 and $1.2 \mathrm{~m} / \mathrm{s}$ and PSA3 participants with gait speed higher than $1.2 \mathrm{~m} / \mathrm{s}$, FFI Foot function index. $\Delta_{1}$ Difference in the FFI total score between PSA2 and PsA3. $\Delta_{2}$ Difference in the FFI total score between PsA1 and PSA2 


\section{Discussion}

The aims of this study were first to assess the differences in gait STPs and gait variability measured with IMUs during a $10-\mathrm{m}$ walk test between participants with PsA and foot pain and age- and sex-matched healthy participants and second to investigate the relationships between gait STPs and variability and clinical outcomes of foot pain and disability.

\section{Spatiotemporal parameters}

Our findings showed significant differences in all the STPs between participants with PsA and matched controls. These differences included lower cadence, gait speed, stride length, swing time, and foot strike angle and higher gait cycle duration and double support time in the PsA group than in the healthy controls. However, only cadence, gait speed, and gait cycle duration remained significantly different after adjusting for BMI. Nearly $50 \%$ of our PsA sample had a BMI above $30 \mathrm{~kg} /$ $\mathrm{m}^{2}$, which is not surprising because obesity is a common comorbidity of PsA [52]. Moreover, obesity is known to alter STPs, which has been suggested to be a strategy to lower joint loadings [53]. Therefore, it is logical that BMI affected the differences in STPs between participants with PsA and controls in our study.

A few previous studies showed some alterations in STPs in people with PsA, but not all of them demonstrated significant differences between PsA participants and healthy controls. It is important to mention that all these studies included participants with a younger mean age compared to that reported in our study. Of note, in a recent systematic review, age was shown to have significant effects on slowing STPs in healthy adults [30]. Thus, the more significant between-group differences demonstrated in the present study could be attributed to a combined effect of age and disease. Moreover, in the study by Hyslop et al., the participants were matched for BMI, which was normal in PsA and control participants [27]. The results reported in our study highlighted the effects of BMI on STP. Moreover, the impact of obesity on foot function and structure in older adults has been demonstrated in a previous study [54]. This suggests that increased BMI could significantly alter foot function and gait in people with PsA which could explain the nonsignificant differences reported in Hyslop. In addition, in this latter study, even though patients with confirmed enthesitis were included, low to moderate levels of foot pain were reported by the authors which can also help explain their findings. In our study, although nearly $90 \%$ of the PsA participants were managed on DMARDs/biologicals and most of them had normal CRP levels, a high prevalence of simultaneous forefoot and rearfoot pain and moderate to severe levels of self-reported foot pain and disability were demonstrated. This finding suggests that even though pharmacological treatments might be efficient on systemic inflammation control, significant foot pain and related disability can still be present in people with PsA.

Furthermore, clinically important differences in STPs between PsA and healthy participants and strong correlations between foot pain, foot function, and STPs, especially gait speed, were also demonstrated. Interestingly, these correlations were not affected by the CRP levels, disease duration, or lower limb pain since none of these clinical parameters was significantly correlated with STP. Although direct comparison between pain levels reported in Hyslop et al. and those reported in the present study cannot be made due to the different measurement tools used, our findings suggest that foot pain may play a major role in gait alterations in people with PsA.

Based on gait speed values, it was possible to discriminate between three PsA subgroups. PsA participants who had gait speed values below $1.0 \mathrm{~m} / \mathrm{s}$ had higher FFI scores than those for whom gait speed was between 1.0 $\mathrm{m} / \mathrm{s}$ and $1.2 \mathrm{~m} / \mathrm{s}$ and those with gait speed above $1.2 \mathrm{~m} /$ s. There was not enough power to statically test the differences in the FFI scores between these three subgroups. However, knowing that the MCID for the FFI total score is 7 points, the results showed that differences between these gait speed-based subgroups could be clinically significant. This suggests that gait speed may be a relevant metric not only to assess gait alteration in people with PsA but also to have more objective insight into the impact of the disease on self-reported foot pain and disability.

The results from studies addressing gait STPs in patients with RA are coherent with our study. For example, a previous systematic review on gait analysis of the lower limb in patients with RA showed that they tend to walk slower, with a longer gait cycle, a shorter step length, a longer double support time, and a lower cadence compared to healthy subjects [55]. These findings were confirmed in a recent meta-analysis that reported a significant decrease in gait speed, stride length, and cadence and a significant increase in double support in patients with RA compared to healthy participants. Similar to the present study, this meta-analysis also reported large effect sizes for the differences between RA and healthy participants (effect sizes $(95 \% \mathrm{CI})$ were 1.55 (0.83 to 2.27 ); 1.66 (1.49 to 1.84 ); 0.97 (0.45 to 1.49 )) and 1.01 (0.66 to 1.36 ) for gait speed, stride length, cadence and double support time, respectively [14].

It appears that walking slower with shorter steps is a common compensatory strategy that people with arthritic foot disease use to reduce loads and pain in the affected joints and to increase stability [53, 56, 57]. It has been reported that reducing gait speed leads to lower joint flexion and extension moments in hip, knee, and 
ankle joints [58] and that reducing step length allows for a decrease in the vertical ground reaction forces [5961]. Moreover, double limb support, in contrast to single limb support and swing (\% GCT), is the most stable phase during gait, and all these parameters represent the ability of the patient to transfer their body weight to the affected limb [62]. Our findings, similar to previous studies in RA patients, showed a significant increase in double support and a reduction in the swing phase [14]. This suggests that spending more time on both feet could be an adaptive approach to increase stability and reduce pain during gait.

\section{Gait variability}

Analysis of gait variability is a clinically relevant parameter in the evaluation of gait and responses to interventions and is a viable option for the quantitative evaluation of gait stability [21]. To our knowledge, gait variability has never been investigated in people with PsA or other populations with foot involvement associated with arthritic joint disease. In our study, the mean stride time variability was higher in the PsA group $(4.49 \pm 3.56 \%)$ than in the control group $(2.32 \pm 0.72 \%)$ and above the normative values reported for stride time variability (1.1 to $2.6 \%$ ) [49], indicating increased gait instability. This is consistent with novel findings from a recent study that reported an increased risk of falling in people with PsA [33]. Increased gait variability and instability could be ascribed to pain, muscle weakness, restricted range of motion, and a decrease in proprioception caused by inflammation in the foot joints and the surrounding structures [20]. However, there were no significant correlations between foot pain and stride time variability. Findings from a recent study reporting a significant alteration of static and dynamic balance in people with PsA also showed that there were no correlations between balance parameters, foot pain and foot function [32]. This suggests that pain may not be a determinant of gait variability and that this metric could be accepted as an independent gait parameter that should be assessed systematically in people with PsA. However, this needs to be confirmed in larger and longitudinal studies. Further studies are also needed to investigate the involvement of muscle weakness, reduced range of motion, and alterations of the proprioceptive system in gait variability in people with PsA.

This study showed that the disease duration and CRP levels were not correlated with self-reported foot pain and function, which is consistent with results from a previous study conducted in people with spondyloarthritis [63]. On the other hand, gait spatiotemporal parameters, especially gait speed, were strongly correlated with these clinical outcomes. It would be relevant to investigate these associations in larger and longitudinal studies and to link gait parameters to clinically relevant domains in PsA as determined by the GRAPPA [64].

Body-worn IMUs for gait analysis are more than ever used in clinical assessment and clinical studies in several neurological diseases, such as Parkinson's disease, stroke, and multiple sclerosis [65-67]. These systems are easy to use, time- and cost-effective, do not require special equipment or expertise, and could be used in different settings. In addition, recent evidence suggests that they could accurately and reliably measure STPs in people with axial spondyloarthritis and PsA [23, 24]. This study suggests that body-worn IMUs could be useful to obtain an objective measure of functional mobility in people with PsA.

There are some limitations to this study. First, given the small sample size and the uneven distribution of males and females in our study sample, the findings cannot be generalized to the population. Second, the patients were included based on their subjective perception of foot involvement. Although from a clinical perspective, the patients' perception of pain and disability is a vital criterion, adding ultrasonography/MRI data to confirm the presence of enthesopathy, tendinopathy, synovitis, and/or bone erosions would have given more insight into the severity of foot involvement. Third, CRP levels were documented from the participant's clinical records, which led to missing data and a delay (up to 3 months in a few participants) between CRP level assessment and data collection. Moreover, important clinical domains, including disease activity, skin disease activity, and fatigue, were not assessed which could significantly limit the proper description of the study cohort. Additionally, it is important to mention that gait variability was assessed over a 10-m distance. Ideally, future studies should consider longer distances while assessing this metric. Finally, the presence or absence of foot deformity was recorded in a qualitative manner (presence/absence). Using standardized tools such as the foot posture index [68] could have been more relevant to ensure comparability between studies.

\section{Conclusion}

Foot pain and disability have been reported to be important manifestations of PsA. This was confirmed in this study since severe levels of foot-related disability were reported despite the use of DMARD/biological therapy in more than $80 \%$ of the patients. Disability was further demonstrated through the objective assessment of foot function. The findings showed that STPs obtained from IMUs during a standardized 10-m walk test were significantly altered and that there were strong correlations between pain, disability levels, and STPs. In addition, this study demonstrated for the first time increased gait variability in people with PsA which was not 
correlated with pain levels. This suggests that instability during gait in PsA could be independent of foot pain and that it should be further assessed in larger studies. The findings of this study add important information on gait in people with PsA, a population for which research on gait and posture is scarce.

\section{Abbreviations}

BMl: Body mass index; CRP: C reactive protein; CV: Coefficient of variation; DMARD: Disease-modifying anti-rheumatic drugs; FFI: Foot function index; GCT: Gait cycle time; MCID: Minimal clinically important difference; NRC: Numerical rating scale; PSA: Psoriatic arthritis; STPs: Spatiotemporal parameters; 10MWT: 10-m walk test

\section{Acknowledgments}

Not applicable.

\section{Authors' contributions}

RW and PB conceived the study. RW collected and analyzed the data and wrote the first full draft of the manuscript. PB assisted with the analysis of data. PB, PD and NG all reviewed the manuscript drafts. All authors read and approved the final manuscript.

\section{Authors' information}

Affiliations:

Faculty of Medicine and Health Sciences, Université de Sherbrooke, Sherbrooke, QC, Canada.

Roua Walha, Nathaly Gaudreaut, Pierre Dagenais and Patrick boissy. Research center on aging, CIUSSS Estrie CHUS, Sherbrooke, QC, Canada. Patrick Boissy.

\section{Funding}

This research was funded by The CANADIAN MSK REHAB RESEARCH NETWORK, CFI-148081.

\section{Availability of data and materials}

The dataset used and analyzed during the current study is available from walha.roua@usherbrooke.ca on reasonable request.

\section{Declarations}

\section{Ethics approval and consent to participate}

The study was approved by the CIUSSS de I'Estrie-CHUS Ethics Board (20193182), and all the participants gave their informed consent to participate in the study.

\section{Consent for publication}

Not applicable.

\section{Competing interests}

The authors declare no conflict of interest. The funders had no role in the design of the study; in the collection, analyses, or interpretation of data; in the writing of the manuscript; or in the decision to publish the results.

Received: 11 September 2021 Accepted: 10 February 2022

Published online: 04 March 2022

\section{References}

1. Bezza A, Niamane R, Amine B, El Maghraoui A, Bensabbah R, Hajjaj-Hassoun $\mathrm{N}$. Involvement of the foot in patients with psoriatic arthritis. A review of 26 cases. Joint Bone Spine. 2004;71(6):546-9. https://doi.org/10.1016/j.jbspin.2 002.06 .001$.

2. Nordbø ECA, Aamodt G, Ihlebæk CM. Subjective health complaints in individuals with psoriasis and psoriatic arthritis: associations with the severity of the skin condition and illness perceptions - a cross-sectional study. Int J Behav Med. 2017;24(3):438-46. https://doi.org/10.1007/s12529-01 7-9637-4.

3. Hyslop E, McInnes IB, Woodburn J, Turner DE. Foot problems in psoriatic arthritis: high burden and low care provision. Ann Rheum Dis. 2010;69(5): 928. https://doi.org/10.1136/ard.2009.111971.
4. Patience A, Helliwell PS, Siddle HJ. Focussing on the foot in psoriatic arthritis: pathology and management options. Expert Rev Clin Immunol 2018;14(1):21-8. https://doi.org/10.1080/1744666X.2018.1413351.

5. Wilkins RA, Siddle HJ, Redmond AC, Helliwell PS. Plantar forefoot pressures in psoriatic arthritis-related dactylitis: an exploratory study. Clin Rheumatol. 2016:35(9):2333-8. https://doi.org/10.1007/s10067-016-3304-z.

6. Polachek A, Li S, Chandran V, Gladman DD. Clinical Enthesitis in a prospective longitudinal psoriatic arthritis cohort: incidence, prevalence, characteristics, and outcome. Arthritis Care Res. 2017;69(11):1685-91. https:// doi.org/10.1002/acr.23174.

7. Turner DE, Hyslop E, Barn R, McInnes IB, Steultjens MPM, Woodburn J. Metatarsophalangeal joint pain in psoriatic arthritis: a cross-sectional study. Rheumatol Oxf Engl. 2014;53(4):737-40. https://doi.org/10.1093/rheuma tology/ket435.

8. Kaeley GS, Eder L, Aydin SZ, Gutierrez M, Bakewell C. Dactylitis: a hallmark of psoriatic arthritis. Semin Arthritis Rheum. 2018;48(2):263-73. https://doi.org/1 0.1016/j.semarthrit.2018.02.002.

9. Carter K, Walmsley S, Chessman D, Rome K, Turner DE. Perspectives of patients and health professionals on the experience of living with psoriatic arthritis-related foot problems: a qualitative investigation. Clin Rheumatol. 2019:38(6):1605-13. https://doi.org/10.1007/s10067-018-04411-2.

10. Leung YY, Ogdie A, Orbai A-M, Tillett W, Coates LC, Strand V, et al. Classification and outcome measures for psoriatic arthritis. Front Med. 2018 ; 5:246. https://doi.org/10.3389/fmed.2018.00246.

11. Doi T, Nakakubo S, Tsutsumimoto K, Kim M-J, Kurita S, Ishii H, et al. Spatiotemporal gait variables predicted incident disability. J Neuroengineering Rehabil. 2020;17(1):11. https://doi.org/10.1186/s12984-020-0643-4.

12. Hyslop E, Woodburn J, McInnes IB, Semple R, Newcombe L, Hendry G, et al. A reliability study of biomechanical foot function in psoriatic arthritis based on a novel multi-segmented foot model. Gait Posture. 2010;32(4):619-26. https://doi.org/10.1016/j.gaitpost.2010.09.004.

13. Turner DE, Helliwell PS, Siegel KL, Woodburn J. Biomechanics of the foot in rheumatoid arthritis: identifying abnormal function and the factors associated with localised disease "impact". Clin Biomech Bristol Avon. 2008; 23(1):93-100. https://doi.org/10.1016/j.clinbiomech.2007.08.009.

14. Carroll M, Parmar P, Dalbeth N, Boocock M, Rome K. Gait characteristics associated with the foot and ankle in inflammatory arthritis: a systematic review and meta-analysis. BMC Musculoskelet Disord. 2015;16:134.

15. Kyrdalen IL, Thingstad P, Sandvik L, Ormstad H. Associations between gait speed and well-known fall risk factors among community-dwelling older adults. Physiother Res Int. 2019;24(1):e1743. https://doi.org/10.1002/pri.1743.

16. Verghese J, Wang C, Holtzer R. Relationship of clinic-based gait speed measurement to limitations in community-based activities in older adults. Arch Phys Med Rehabil. 2011;92(5):844-6. https://doi.org/10.1016/j.apmr.201 0.12 .030 .

17. Studenski S, Perera S, Patel K, Rosano C, Faulkner K, Inzitari M, et al. Gait speed and survival in older adults. JAMA. 2011;305(1):50-8. https://doi.org/1 0.1001/jama.2010.1923

18. Fritz S, Lusardi M. White paper: "walking speed: the sixth vital sign". J Geriatr Phys Ther. 2009;32(2):46-9.

19. Middleton A, Fritz SL, Lusardi M. Walking speed: the functional vital sign. J Aging Phys Act. 2015;23(2):314-22. https://doi.org/10.1123/japa.2013-0236.

20. Hausdorff JM. Gait variability: methods, modeling and meaning. J NeuroEngineering Rehabil. 2005;2(1):19. https://doi.org/10.1186/17430003-2-19.

21. Hamacher D, Singh NB, Van Dieën JH, Heller MO, Taylor WR. Kinematic measures for assessing gait stability in elderly individuals: a systematic review. J R Soc Interface. 2011;8(65):1682-98. https://doi.org/10.1098/rsif.2 011.0416 .

22. Hausdorff JM, Rios DA, Edelberg HK. Gait variability and fall risk in community-living older adults: a 1-year prospective study. Arch Phys Med Rehabil. 2001;82(8):1050-6. https://doi.org/10.1053/apmr.2001.24893.

23. Walha R, Lebel K, Gaudreault N, Dagenais P, Cereatti A, Della Croce U, et al. The accuracy and precision of Gait Spatio-temporal parameters extracted from an instrumented sock during treadmill and Overground walking in healthy subjects and patients with a foot impairment secondary to psoriatic arthritis. Sensors. 2021;21(18):6179. https://doi. org/10.3390/s21186179.

24. Soulard J, Vaillant J, Balaguier R, Baillet A, Gaudin P, Vuillerme N. Foot-worn inertial sensors are reliable to assess spatiotemporal Gait parameters in axial Spondyloarthritis under single and dual task walking in axial 
Spondyloarthritis. Sensors. 2020;20(22):6453. https://doi.org/10.3390/s202264 53.

25. Soulard J, Vaillant J, Agier C-T, Vuillerme N. Gait characteristics in patients with ankylosing spondylitis: a systematic review. Clin Exp Rheumatol. 2021; 39(1):173-86.

26. Soulard J, Vaillant J, Baillet A, Gaudin P, Vuillerme N. Gait and axial Spondyloarthritis: comparative Gait analysis study using foot-worn inertial sensors. JMIR MHealth UHealth. 2021;9(11):e27087. https://doi.org/10.2196/27087.

27. Hyslop E. Biomechanics of enthesitis of the foot in psoriatic arthritis [Internet] [Ph.D.]. Glasgow Caledonian University; 2013 [cited 2021 Oct 16]. Available from: https://ethos.bl.uk/OrderDetails.do?uin=uk.bl.ethos.601641

28. Woodburn J, Hyslop E, Barn R, Mclnnes IB, Turner DE. Achilles tendon biomechanics in psoriatic arthritis patients with ultrasound proven enthesitis. Scand J Rheumatol. 2013;42(4):299-302. https://doi.org/10.3109/ 03009742.2012 .747626$.

29. van der Leeden M, Steultjens M, Dekker JHM, Prins APA, Dekker J. The relationship of disease duration to foot function, pain and disability in rheumatoid arthritis patients with foot complaints. Clin Exp Rheumatol. 2007;25(2):275-80.

30. Herssens N, Verbecque E, Hallemans A, Vereeck L, Van Rompaey V, Saeys W. Do spatiotemporal parameters and gait variability differ across the lifespan of healthy adults? A systematic review. Gait Posture. 2018;64:181-90. https:// doi.org/10.1016/j.gaitpost.2018.06.012.

31. Amor-Dorado JC, Barreira-Fernandez MP, Llorca J, Gonzalez-Gay MA. Oculographic, clinical test of sensory integration and balance and computerized dynamic Posturography findings in patients with psoriatic arthritis. Otol Neurotol Off Publ Am Otol Soc Am Neurotol Soc Eur Acad Otol Neurotol. 2017;38(3):448-53. https://doi.org/10.1097/MAO. 0000000000001296.

32. Duruoz MT, Baklacioglu HS, Sanal Toprak C, Gencer Atalay K, Atagunduz MP. The evaluation of the static and dynamic balance disorders in patients with psoriatic arthritis. Rheumatol Int. 2018;38(11):2063-8. https://doi.org/10.1007/ s00296-018-4137-7.

33. Carter K, Walmsley S, Oliffe M, Hassett G, Turner DE. Increased falls risk in people with psoriatic arthritis-related foot problems: a novel finding. Rheumatol Oxf Engl. 2021;60(2):976-7. https://doi.org/10.1093/rheuma tology/keaa654.

34. Stanmore EK, Oldham J, Skelton DA, O'Neill T, Pilling M, Campbell AJ, et al. Risk factors for falls in adults with rheumatoid arthritis: a prospective study. Arthritis Care Res. 2013;65(8):1251-8. https://doi.org/10.1002/acr.21987.

35. Boonstra AM, Stewart RE, Köke AJA, Oosterwijk RFA, Swaan JL, Schreurs KMG, et al. Cut-off points for mild, moderate, and severe pain on the numeric rating scale for pain in patients with chronic musculoskeletal pain: variability and influence of sex and catastrophizing. Front Psychol. 2016;7: 1466. https://doi.org/10.3389/fpsyg.2016.01466

36. Mills $K$, Hunt MA, Ferber R. Biomechanical deviations during level walking associated with knee osteoarthritis: a systematic review and meta-analysis. Arthritis Care Res. 2013;65(10):1643-65. https://doi.org/10.1002/acr.22015.

37. Bahl JS, Nelson MJ, Taylor M, Solomon LB, Arnold JB, Thewlis D. Biomechanical changes and recovery of gait function after total hip arthroplasty for osteoarthritis: a systematic review and meta-analysis. Osteoarthr Cartil. 2018;26(7):847-63. https://doi.org/10.1016/j.joca.2018.02. 897.

38. Eitzen I, Fernandes L, Kallerud H, Nordsletten L, Knarr B, Risberg MA. Gait characteristics, symptoms, and function in persons with hip osteoarthritis: a longitudinal study with 6 to 7 years of follow-up. J Orthop Sports Phys Ther. 2015;45(7):539-49. https://doi.org/10.2519/jospt.2015.5441.

39. Demirel A, Onan D, Oz M, Ozel Aslıyuce Y, Ulger O. Moderate disability has negative effect on spatiotemporal parameters in patients with chronic low back pain. Gait Posture. 2020;79:251-5. https://doi.org/10.1016/j.gaitpost.202 0.05.015.

40. Budiman-Mak E, Conrad KJ, Roach KE. The foot function index: a measure of foot pain and disability. J Clin Epidemiol. 1991;44(6):561-70. https://doi.org/1 0.1016/0895-4356(91)90220-4

41. Agel J, Beskin JL, Brage M, Guyton GP, Kadel NJ, Saltzman CL, et al. Reliability of the Foot Function Index: A report of the AOFAS Outcomes Committee. Foot Ankle Int. 2005;26(11):962-7. https://doi.org/10.1177/10711 0070502601112 .

42. Pourtier-Piotte C, Pereira B, Soubrier M, Thomas E, Gerbaud L, Coudeyre E. French validation of the foot function index (FFI). Ann Phys Rehabil Med. 2015;58(5):276-82. https://doi.org/10.1016/j.rehab.2015.07.003.
43. Comprehensive Gait and Balance Analysis - APDM Wearable Technologies [Internet]. APDM. 2020 [cited 2021 Jun 18]. Available from: https://apdm. $\mathrm{com} / \mathrm{mobility/}$

44. Tunca C, Pehlivan N, Ak N, Arnrich B, Salur G, Ersoy C. Inertial sensor-based robust Gait analysis in non-hospital settings for neurological disorders. Sensors. 2017;17(4):825. https://doi.org/10.3390/s17040825.

45. Morris R, Stuart S, McBarron G, Fino PC, Mancini M, Curtze C. Validity of mobility lab (version 2) for gait assessment in young adults, older adults and Parkinson's disease. Physiol Meas. 2019;40(9):095003. https://doi.org/10.1 088/1361-6579/ab4023.

46. Schmitz-Hübsch T, Brandt AU, Pfueller C, Zange L, Seidel A, Kühn AA, et al. Accuracy and repeatability of two methods of gait analysis - GaitRite ${ }^{T M}$ und mobility lab $\mathrm{b}^{\mathrm{TM}}$ - in subjects with cerebellar ataxia. Gait Posture. 2016;48:194201. https://doi.org/10.1016/j.gaitpost.2016.05.014.

47. Washabaugh EP, Kalyanaraman T, Adamczyk PG, Claflin ES, Krishnan C. Validity and repeatability of inertial measurement units for measuring gait parameters. Gait Posture. 2017;55:87-93. https://doi.org/10.1016/j.gaitpost.2 017.04.013.

48. Salarian A, Russmann H, Vingerhoets FJG, Dehollain C, Blanc Y, Burkhard PR, et al. Gait assessment in Parkinson's disease: toward an ambulatory system for long-term monitoring. IEEE Trans Biomed Eng. 2004;51(8):1434-43. https://doi.org/10.1109/TBME.2004.827933.

49. König N, Taylor WR, Baumann CR, Wenderoth N, Singh NB. Revealing the quality of movement: a meta-analysis review to quantify the thresholds to pathological variability during standing and walking. Neurosci Biobehav Rev. 2016;68:111-9. https://doi.org/10.1016/j.neubiorev.2016.03.035.

50. Cohen J. Statistical power analysis for the behavioral sciences. 2nd ed. New York: Routledge; 1988. 567 p.

51. Bohannon RW, Williams AA. Normal walking speed: a descriptive metaanalysis. Physiotherapy. 2011;97(3):182-9. https://doi.org/10.1016/j.physio.201 0.12 .004 .

52. Kumthekar A, Ogdie A. Obesity and psoriatic arthritis: a narrative review. Rheumatol Ther. 2020;7(3):447-56. https://doi.org/10.1007/s40744-020-0021 $5-6$.

53. Runhaar J, Koes BW, Clockaerts S, Bierma-Zeinstra SMA. A systematic review on changed biomechanics of lower extremities in obese individuals: a possible role in development of osteoarthritis. Obes Rev Off J Int Assoc Study Obes. 2011;12(12):1071-82. https://doi.org/10.1111/j.1467-789X.2011. 00916.x.

54. Mickle KJ, Steele JR. Obese older adults suffer foot pain and foot-related functional limitation. Gait Posture. 2015;42(4):442-7. https://doi.org/10.1016/ j.gaitpost.2015.07.013.

55. Baan H, Dubbeldam R, Nene AV, van de Laar MAFJ. Gait analysis of the lower limb in patients with rheumatoid arthritis: a systematic review. Semin Arthritis Rheum. 2012;41(6):768-788.e8.

56. Mündermann A, Dyrby CO, Hurwitz DE, Sharma L, Andriacchi TP. Potential strategies to reduce medial compartment loading in patients with knee osteoarthritis of varying severity: reduced walking speed. Arthritis Rheum. 2004;50(4):1172-8. https://doi.org/10.1002/art.20132.

57. Valderrabano V, Nigg BM, von Tscharner V, Stefanyshyn DJ, Goepfert B, Hintermann B. Gait analysis in ankle osteoarthritis and total ankle replacement. Clin Biomech Bristol Avon. 2007;22(8):894-904. https://doi. org/10.1016/j.clinbiomech.2007.05.003.

58. Lelas JL, Merriman GJ, Riley PO, Kerrigan DC. Predicting peak kinematic and kinetic parameters from gait speed. Gait Posture. 2003;17(2):106-12. https:// doi.org/10.1016/S0966-6362(02)00060-7.

59. Frederick EC, Hagy JL. Factors affecting peak vertical ground reaction forces in running. J Appl Biomech. 1986;2(1):41-9. https://doi.org/10.1123/ijsb.2.1.41.

60. Martin PE, Marsh AP. Step length and frequency effects on ground reaction forces during walking. J Biomech. 1992;25(10):1237-9. https://doi.org/10.101 6/0021-9290(92)90081-B.

61. Debi R, Mor A, Segal O, Segal G, Debbi E, Agar G, et al. Differences in gait patterns, pain, function and quality of life between males and females with knee osteoarthritis: a clinical trial. BMC Musculoskelet Disord. 2009;10(1):127. https://doi.org/10.1186/1471-2474-10-127.

62. Winter DA, Patla AE, Frank JS, Walt SE. Biomechanical walking pattern changes in the fit and healthy elderly. Phys Ther. 1990;70(6):340-7. https:// doi.org/10.1093/ptj/70.6.340.

63. Ozaras N, Havan N, Poyraz E, Rezvanı A, Aydın T. Functional limitations due to foot involvement in spondyloarthritis. J Phys Ther Sci. 2016;28(7):2005-8. https://doi.org/10.1589/jpts.28.2005. 
64. Ogdie A, de Wit M, Duffin KC, Campbell W, Chau J, Coates LC, et al. Defining outcome measures for psoriatic arthritis: a report from the GRAPPA-OMERACT working group. J Rheumatol. 2017;44(5):697-700. https:// doi.org/10.3899/jheum. 170150.

65. Brognara L, Palumbo P, Grimm B, Palmerini L. Assessing Gait in Parkinson's disease using wearable motion sensors: a systematic review. Dis Basel Switz. 2019;7(1):E18. https://doi.org/10.3390/diseases7010018.

66. Pollet J, Buraschi R, Villafañe JH, Piovanelli B, Negrini S. Gait parameters assessed with inertial measurement unit during 6-minute walk test in people after stroke. Int J Rehabil Res Int Z Rehabil Rev Int Rech Readaptation. 2021;44(4):358-63. https://doi.org/10.1097/MRR. 0000000000000498.

67. Vienne-Jumeau A, Quijoux F, Vidal P-P, Ricard D. Wearable inertial sensors provide reliable biomarkers of disease severity in multiple sclerosis: a systematic review and meta-analysis. Ann Phys Rehabil Med. 2020:63(2):13847. https://doi.org/10.1016/j.rehab.2019.07.004.

68. Keenan A-M, Redmond AC, Horton M, Conaghan PG, Tennant A. The foot posture index: Rasch analysis of a novel, foot-specific outcome measure. Arch Phys Med Rehabil. 2007;88(1):88-93. https://doi.org/10.1016/j.apmr.2 006.10.005.

\section{Publisher's Note}

Springer Nature remains neutral with regard to jurisdictional claims in published maps and institutional affiliations.

Ready to submit your research? Choose BMC and benefit from:

- fast, convenient online submission

- thorough peer review by experienced researchers in your field

- rapid publication on acceptance

- support for research data, including large and complex data types

- gold Open Access which fosters wider collaboration and increased citations

- maximum visibility for your research: over $100 \mathrm{M}$ website views per year

At $\mathrm{BMC}$, research is always in progress.

Learn more biomedcentral.com/submissions 